\title{
An Innovation in Incorporating Computers into Accounting Curricula
}

\author{
M. C. ER \\ King Fahd University of \\ Petroleum and Minerals \\ Dhahran, Saudi Arabia
}

\author{
and
}

A. C. NG

La Trobe University

Bundoora 3083

Australia

\begin{abstract}
The rapid advances of information technology, coupled with the rapid falling prices of personal computers, offer a challenge and an opportunity to incorporating computers into accounting curricula. This paper presents a detailed list of computerrelated topics as core units that should be integrated into accounting curricula. The course description for each of the core computer courses is provided. Detailed justifications for their inclusions are also given. The computer resources required for implementing the computer-related units are discussed at length. Finally, a bootstrap process for solving the shortage of qualified faculty who have expertise in both accounting and computer science fields is suggested.
\end{abstract}

\section{Introduction}

With the advances of computer technology and the rapid falling prices of personal computers, the utilization of computers in big corporations and small businesses becomes more widespread. This is most noticeable following the abundent availability of business packages, such as word processing, spreadsheets, accounting software, etc. A small business employing a few employees, nowadays, can afford to own a personal computer with some business software packages to produce business letters on a high quality laser printer, and perhaps to process business transactions, such as sending out invoices, internal book-keeping of accounts, etc. The emphasis on human-computer interface has yielded fruitful results-software packages have be come more user-friendly and hence easier to use. As a result, more novice-users are attracted to use computers at workplaces, and are increasingly expected to be computer literate. By the present day standard, personal computer are also found in the "better-than-the-average" primary and secondary schools, running commercially available software packages and supporting computer programming. 
Meanwhile, in universities and colleges, accounting faculty are increasingly face with the challenge of incorporating computer related topics into accounting curricula (Cerullo, Topiol, \& Klein, 1989; Klein, Cerullo, \& Cerullo, 1991), adapting to changing technologies and the availability of new information technologies, al though these processes were spearheaded by data processing in the 60's. The debate continues on how best to incorporate computer into accounting curricula in a way coherent (Bhaskar, 1982; Bhaskar, 1983; Bhaskar \& Kaye, 1985; Buttermuch, 1991; Collier, Kaye, Sapul, \& Williams, 1990; Collins, 1983; Er \& Ng, 1989; Hopewell \& Myklebust, 1984; Kaye \& Nicholson, 1992; Romney, 1983), taking into account various guidelines issued by many interesting parties (AECC, 1990; AAA, 1986; AACSB, 1989; AICPA, 1990; BECPAF, 1989). To keep up with the rapid pace of development in information technologies, almost every five to eight years, accounting curricula need to be substantially revised in order to ensure their continued relevance to the accounting profession. These revisions obviously have to take into consideration the impact of information technology on business organizations (Er, 1987; Simon, 1990), and the needs of practicing accounting professionals in performing their daily routines (Wailer $\&$ Gallum, 1985).

To overcome the temporary shortage of qualified auditors who have in-depth knowledge of computer hardware and software, all Big Six accounting firms employ staff of computer experts to assist auditors in dealing with auditing of computer-based accounting information systems. For example, Coopers and Lybrand has a separate division called Computer Audit Assistance Group (CAAG) which is used on any audits where auditors feel that they are not equipped to deal with technical details at the machine level. This approach, however, requires a group of EDP auditors and another group of computer experts to work very closely and to collaborate on all technical aspects. Unfortunately, knowledge gaps do exist between these two groups of experts, despite the need to speak a common language with technical jargons. Ideally, it would be better if accounting professionals could possess essential core know ledge of computer technologies, and rely less on computer experts for assistance. The situation is more acute for accounting professionals working in small businesses where advices of computer experts are not readily available.

In what follows, we present a revised list of core computing units that should be incorporated into any accounting curricula, and their justifications, using a model of four-year accounting degree program. The computer resources needed and the faculty required to implement fully the suggested computing units are discussed. The curriculum model presented is meant to be coherent and consistent, irtertwining with other accounting topics. This is intended as a Contribution to the unavoidable revision of accounting curricula in the new era of information revolution, as the development of accounting curricula continues.

\section{Incorporating Computers into Accounting Curricula}

Our principal objectives in incorporating computers into accounting curricula are twofold: (a) to support the needs of practicing accounting professionals who are increasingly dependent on computers to perform their works; (b) to demystify computers as black boxes. Each of which is now discussed in turn. 


\section{(a) The Needs of Accounting Professionals}

The fundamental reason for incorporating computers into accounting curricula is the increased reliance on computers to provide accounting information to management for decision making. Computer-based accounting information systems there fore form the core of accountants' work. To conduct computer audits on such accounting information systems effectively, it is necessary to understand the fundamentals of data processing, database technologies, and computer networks in order to exercise controls.

On the other hand, managers, regardless of seniority, are increasingly relying on computers for decision making. Accountants, who are often called upon to assist senior executives in decision making, are expected to be computer literate, especially in enduser computing and computer-based accounting information systems areas, preferably also in the areas of decision support systems and expert systems.

From the above discussions, it does seem that computing, just like business laws, finance, management, and economics, has become one of the essential knowledge bases that any practicing accounting professionals are reasonably expected to know and equip with. Needless to say, accountants who know nothing about computers will find it hard to fit into the mainstream of accounting profession. In fact, the Big Six accounting firms published in 1989 a white paper, entitled "Perspectives on Education: Capabilities for Success in the Accounting Profession", calling for greater in corporation of computer topics into accounting curricula.

\section{(b) The Demystification of Computers}

In the face of computer frauds and computer crimes, computers should not be treated as black boxes by accounting professionals, if they want to be able to perform auditing on computer-based accounting information systems. To demystify computers, it is necessary to gain a fundamental understanding of the internal workings of computers through computer programming, data processing, computer architecture, and systems programming. Without such a fundamental understanding, accounting professionals would be too afraid to go down to the machine level to examine controls. Sometimes, it may be necessary to inspect machine code, and perhaps to decompile binary code using reverse engineering, in order to find out what is really going on.

With these in mind, it appears that the following topics form the core materials for understanding computing and using computers effectively, and should be incorporated into all accounting curricula accordingly:

(i) Computer Programming;

(ii) End-User Computing;

(iii) Information Processing;

(iv) Computer Systems and Systems Software;

( v ) Databases;

(vi) Computer Networks;

(vii) Computer-Based Accounting Information Systems;

(viii) Computer Auditing;

(ix) Expert Decision Support Systems. 
A more detailed description of the computer topics within a four-year accounting degree program, together with the resources needed to implement them, are presented in Appendix A. Justifications for their inclusion are discussed more fully below.

\section{Computer Programming}

Computer programming is the most fundamental element of computer science, and surprisingly is also the most difficult part of computer science to master. Studying computer programming is the most direct and effective way to understand how to direct a computer to do what one wants it to do. It also exposes students to software bugs (programming errors), thus gaining a better insight into problems confronting computerbased accounting information systems and computer auditing at a large stage. Needless to say, it lays the most important ground work for the subsequent understanding of information processing, computer architecture, systems software, and various advanced topics in computer science. Furthermore, it introduces students to the process of algorithmic thinking as opposed to the illustrative approach used in book-keeping and ledger entries. In order to cope with unfamiliarity in computer programming, hands-on experience in programming a computer is considered absolutely essential. In other words, the supervised laboratory component forms an integrated part of the course unit. During the supervised hours, students can get as much help as possible from instructors in relation to trivial errors such as syntactic errors, system errors, programming errors, etc.

\section{End-User Computing}

The most commonly used applications to run on personal computers are not accounting information systems, but surprisingly, are word processing, followed by spreadsheets, and then databases. Such an observation has been independently confirmed by Wailer and Gallum (1985), who found that more business firms desire these applications be included in accounting curricula. The logic is simple: the low-cost personal computers coupled with abundant business software have made the computer one of the essential tools in conducting businesses, just like the telephone does. Without a formal training in end-user computing, most accounting professionals can only hope to become computer amateurs, who use two fingers in typing-a most time wasteful exercise in using personal computers. A proper training in end-user computing not only improves the productivity of accounting professionals in the long run, but also enhances their professional images as well. Thus most popular applications software packages should be covered in this course unit.

\section{Information Processing}

Information processing forms the bulk of the business use of computers, and is traditionally known as business data processing. It heavily involves file processing and external sorting, dealing with sequential, indexed sequential, and random access files in great detail, and may be regarded as a sequel of the computer programming course. As such, a common programming language should be used in both course units. Since COBOL is still the most commonly used programming language in business data processing, it should be taught to accounting students. However, it is worth pointing out that COBOL is not the best language for computer programming, but it suffices to serve the purpose of business data processing. 


\section{Computer Systems and Systems Software}

A part from the software aspect of computer science, accounting students should also know about the hardware aspect of it in order to fill the gap of knowledge in computers. However, the main purpose is not to train them to become computer scientists, but to expose them to the internal operations of computers and their related systems Software. Thus, in this course unit, accounting students should learn about computer architecture, assembly language, and aspects of compilers, linking loader and operating systems. It is essential that accounting students gain a thorough understanding of the internal workings of a computer in order to handle computers with confidence. In this instance, learning assembly language is a means to an end to gain that understanding.

\section{Databases}

A part from business data processing, database applications are the major use of computers in business environments, as data and information need to be stored in databases rather than scattering everywhere in various file structures: In database design, although the relational approach offers the simplest conceptual model, other approaches, such as hierarchical and networking, are also in use. Thus it is necessary to cover all different approaches to database design, but with an emphasis on the relational model. On top of these, it is also necessary to cover database management systems (DBMS's), and data modeling, including entity-relationship, distributed databases, object-oriented databases, etc.

\section{Computer Networks}

Stand alone computers are less useful as they cannot communicate with each other, and share resources and information. Business activities, by their very nature, require communication and transmission of information. With distributed databases becoming commonplace, computer networks become crucial, especially in large corporations, as they form the back-bone and highway of data communications. Accounting students should be taught local-area network (LAN) and wide-area net work (WAN) technologies so that they are adequately prepared for the challenge of dealing with diversified and distributed computing environments linked by some kind of highspeed networks, including fiber optic. It is not uncommon to find big corporations, especially multi-national ones, using distributed databases linked with wide-area networks, sometimes via satellites.

\section{Computer-Based Accounting Information System}

We now come to the crux of the matter-computer-based accounting information systems - which forms the life-blood of business corporations in terms of information flow. The primary purpose of accounting information systems is to transform raw data into useful accounting information for management decision making. It is within this context that the accounting professionals' responsibilities lie: to ensure the integrity and consistency of computer-based accounting information systems. Accounting professionals are expected to completely familiarize themselves with accounting information Systems, both computer-based and manual-based, in order to exercise essential controls at strategic points of the information systems (Davis, 1968; Walsh, 1986). It is within the context of computer-based accounting information systems that most of the skills and knowledge on computers come into play. 


\section{Computer Auditing}

Computer auditing is important for both internal and external purposes. Beside ensuring the soundness of accounting information systems for internal control purposes, it also has to satisfy legislation requirements under company acts. Thus accounting students need to be taught the compliance and substantive tests, and be able to carry out those tests in EDP environments (Davis, 1968; Vasarhelyi \& Lin, 1985), as some of them may become auditors in future. A study of computer-based accounting information systems cannot be considered complete until accounting students also know how to conduct computer auditing.

\section{Expert Decision Support Systems}

Expert systems and decision support systems (DSS's) have been around for some times, but their influence on management decision making and accounting professionals only starts to take effect in recent years (Abdolmohammadi, 1987). The increase in dependence on computers to make business judgements, regardless of whether computers provide only some forms of assistance, means that accounting professionals should know how computer advices are derived, and hence the extent of their validity and limitations, not just use them blindly. Otherwise, the good old "garbage-in garbageout" symptom will recur. On the other hand, knowing how expert systems and DSS's work, accounting professionals can put them into better use, not just use them more effectively. The emerging trend of combining expert systems and DSS's into expert decision support systems (EDSS's) means that accounting students should also be made aware of the new opportunity and challenge, especially in the group decision making context.

\section{Computer Resources Required}

To incorporate computers into accounting curricula successfully, two major factors need to be considered carefully: the first one is computer resources; including both hardware and software; the second one is faculty's expertise. We discuss the former in this section, and return to a discussion on the latter in the next section.

Accounting students need to be exposed to both mainframe computers and personal computers in order to gain the necessary experiences in both contexts. As a minimum, accounting students need to be able to access a mainframe computer; generally operated by a computer center, and a cluster of personal computers, ideally set up as a programming laboratory. The cluster of personal computers should be connected with a local-area network, ideally also linked to the mainframe computer via a campus back-bone network. Such a set-up would permit accounting students to access the mainframe computer via personal computers, and thus the requirements of (obsolete) terminals can be dispensed with. Needless to say, such a mixture of computers in a networked environment is typical in present day business organizations and most wellequipped universities. It offers accounting students a rich environment to learn about different computer architecture, systems software, business applications packages, centralized and distributed databases, computer networks, expert systems, DSS's, programming different types of computers, implementation of computer-based accounting information systems and their controls and audits, etc. More importantly, all these learning processes can take place in a supervised laboratory where instructors are readily available to provide helpful advices, thus reducing the time it takes td acquire new skills and knowledge. 
The supervised laboratory can be constructed as part of the department of accounting if resources permit. In this case, a support programmer would be required to look after the computer laboratory, including installation of software and trouble shooting. Alternatively, it can be constituted as part of the computer center. In this case, a high level of support and commitments from the staff of the computer center would be required. In some instances, if a friendly cooperation can be achieved between the department of accounting and the department of computer science, accounting students can utilize the computer facilities of department of computer science, provided the latter has surplus of computer resources in terms of time slots. In this case, the computer resources required of the department of accounting would be minimal.

Finally, a list of software resources needed for each course unit is presented in Appendix A.

\section{Expertise of Accounting Faculty}

As mentioned above, the second major factor for a successful incorporation of computers into accounting curricula is accounting faculty's expertise in computer areas. However, this is almost the "chicken and eggs" problem. Faculty who are knowledgeable in both accounting and computer science fields are rare - in fact, these are what we try to produce. This is a serious and common problem faced by most departments of accounting (Buttermilch, 1991; Hopewell \& Myklebust, 1984). It seems that the easiest way out is to adopt a bootstrapping strategy: on the one hand, try to appoint faculty from allied fields, such as information systems and computer science, to teach more computer-related course units, if they also possess some accounting knowledge; on the other hand, try to encourage accounting faculty to learn how to program computers, not just learn how to use computers, so that they can gradually incorporate computers into accounting curricula.

The other viable approach is to simply prescribe information systems and computer science; course units offered by other departments that are similar (or near) in contents to those listed in Appendix A as compulsory units for accounting students. In a matter of a decade or so later, students equipped with accounting and computer knowledge will gradually come out of the other end of the education system to fill up accounting faculty positions. The shortage of accounting faculty with computer expertise will then gradually resolve. Bootstrapping is a slow and lengthy process, which cannot be rushed. Patience is the virtue in this case.

\section{Conclusion}

Following the rapid falling prices of personal computers over the past decade, hardware resources are made more affordable to the average departments of accounting. It is suggested that computers should be more extensively integrated into accounting curricula, not just using spreadsheets in elementary accounting courses. The anavoidable trend of development is that accounting information systems are increasingly more dependent on computers to process information. As a consequence, employers increasingly expect accounting professionals to be computer literate and be able to control and audit computer-based accounting information systems.

Based on the current information technologies, a list of core computer topics that should be incorporated into accounting curricula is put forward. The list is based on the needs of practicing accounting professionals to discharge their duties and to fulfill their 
professional obligations when dealing with computer-based accounting information Systems. It also takes into consideration the needs to demystify computers as black boxes in order to gain a better understanding of the internal workings of computers. For completeness sake, the course description for each of the core computer courses is included in Appendix B. Based on the authors' experience, the list of core computer topics can be comfortably incorporated into accounting curricula without the need of double majoring in accounting and computer science.

The computer resources, both hardware and software, required for implementing the computer course units are detailed. It is found that a supervised laboratory in which accounting students can gain hands-on experience in using and programming computers is the minimum resources required. The need for immediate feedback of errors to students by instructors manning the supervised laboratory is essential for enhancing the learning process.

Finally, a bootstrap process that will gradually ease the shortage of experienced faculty who are knowledgeable in both accounting and computer science is suggested. It takes at least a decade to gradually solve the shortage expertise problem.

Anyhow, every five to eight years, accounting curricula need to be revised in order to keep up with the advances of information technologies, if they are to remain professionally and socially relevant.

\section{Acknowledgements}

The use of KFUPM's and LTU's facilities in undertaking this research and in prepaying this paper is gratefully acknowledged, The authors would also like to thank the two anonymous referees for their constructive comments which helped to improve the form and contents of this paper.

\section{References}

Abdolmohammadi, M. j. (1987). Decision Support and Expert Systems in Auditing: A Review and Research Directions. Accounting and Business Research, 17, 173-185.

Accounting Education Change Commission (AECC) (1990). Objectives of Education for Accountants, (September).

American Accounting Association (AAA) (1986). Future Accounting Education: Preparing for the Expanded Profession. Issues in Accounting Education, (Spring), 169-190.

Anserican Assembly of Collegiate Schools of Business (AACSB) (1989). Achieving Quality and Continuous Improvement through Self-Evaluation and Peer Review: Standards for Business and Accounting Accreditation. St. Louis, MOAACSB.

American Institute of Certified Public Accountants (AICPA) (1990). Education Requirements for Entry into the Accounting Profession. New York, NY: AICPA.

Bhaskar, K. N. (1982). Use of Computers in Accountancy Courses. Accounting and Business Research, 13, 3-10.

Bhaskar, K. N. (1983). Computers and the Choice for Accounting Syllabuses. Accounting and Business Research, 13, 83-93.

Bhaskar, K. N. and Kaye, G. R. (1985). Computers and Accountancy Courses: A Reply to Collins. Accounting and Business Research, 15, 239-240.

Big Eight CPA Firms (BECPAF) (1989). Perspectives on Education: Capabilities for Success in the Accounting Profession. Big Eight CPA Firm's White Paper.

Buttermilch, R. (1991). Using Computers in Accounting. Business Education Forum, 45, 39-40 (February).

Cerullo, M., Topiol, J. and Klein, L. A. (1989). Personal Computer Usage in Community College Accounting Courses. Computers and Education, 13, 265-270. 
Collier, P. A., Kaye, G. R., Spaul, B. J. and Williams, B. C. (1990). The Use of Computers in Accountancy Courses: A New Perspective - A Comment. Accounting and Business Research, 20, 353-354.

Collins, R. (1983). Computers and Accountancy Courses: A Comment. Accounting and Business Research, 13, 313-315.

Davis, G. (1968). Auditing and EDP. American Institute of Certified Public Accountants.

Er, M. C. (1987). The Impact of Information Technology on Organizations. Journal of Systems Management, 38, 32-37 (April).

Er, M. C. and Ng, A. C. (1989). The Use of Computers in Accountancy Courses: A New Perspective. Accounting and Business Research, 19, 319-326. 
Hopewell, R. J. and Myklebust, H. N. (1984). Stimulating Faculty to Use Computers. Journal of Accounting Education, 2, 161-162.

Kaye, G. R. and Nicholson, A.H.S. (1992). An Educational Framework for Information Technology in Accounting and Management Education. Computers and Education, 19, 105-112.

Kelin, L. A., Cerullo, M. J. and Cerullo, M. V. (1991). Comparative Longitudinal Study on Microcomputer Availability and Usage in Accounting Curriculums. Computers and Education, 16, 257-265.

Romney, M. (1983). The Use of Microcomputers in Accounting Education. Journal of Accounting Education, 1,11-19.

Simon, H. A. (1990). Information Technology and Organizations. Accounting Review, 65, 658667.

Vasarhelyi, M. A. and Lin, W. T. (1985). EDP Auditing Instruction Using an Interactive Generalized Audit Software. Journal of Accounting Education, 3, 79-89.

Waller, T. C. and Gallum, R. A. (1985). Microcomputer Competency Requirements in the Accounting Industry: A Pilot Study. Journal of Accounting Education, 3, 31-40.

Walsh, J. A. (1986). Empirical Evidence on Internal Control in Microcomputer-based Accounting Information Systems. Accounting and Business Research, 16, 227-233. 


\section{APPENDIX A}

The Core Computer Topics In Accounting Curricula

This is a complete list of core computer topics that should be incorporated into accounting curricula to assist accounting students in understanding aspects of computers and their applications to accounting practices. The computer resources required are also indicated.

Year 1.

1. Computer Programming

$\begin{array}{cc}\text { Supervised } & \text { Computer } \\ \text { Lab Hours } & \text { Resources } \\ \text { (hrs/wk) } & \end{array}$

(This is a beginners' course on computer programming introducing students to the COBOL programming language and programming problem solving).

\section{End-User Computing}

(This course introduces students to popular business applications packages in a business setting).

Year 2.

3. Information Processing

(This is an advanced course on computer programming with specific applications to business data processing using sequential, indexed sequential, and random access files).

4. Computer systems and systems Software

(This course emphasizes computer architecture through assembly programming, with an introduction to operating systems and compilers).

2 Word processor and Spreadsheet

COBOL

Assembly

Language

DBMS

3.

5. Databases

This course includes relational, hierarchical, and networking approaches to database design, and DBMS, as well as data modeling techniques).

6. Computer Networks

(Both local-area networks and wide-area networks are covered, including their hardware and software aspects).

\section{Computer-Based Accounting Information Systems}

(Computer-based accounting information systems are taught showing data and information flows in organizations with controls).

\section{Year 4.}

\section{Computer Auditing}

(Computer auditing of computer-based accounting information systems is taught with an emphasis on the compliance and the substantive tests in EDP environments).

\section{Expert Decision Support Systems}

(This course introduces students to expert systems decision support systems, and expert decision support Systems, with applications to management decision making).

$\begin{array}{cc}2 & \begin{array}{r}\text { Network H/W } \\ \text { and S/W }\end{array} \\ 2 & \begin{array}{c}\text { Accounting } \\ \text { package }\end{array} \\ 2 \quad & \begin{array}{c}\text { Auditing } \\ \text { software }\end{array} \\ 3 & \text { DSS with Expert } \\ & \text { systems shell }\end{array}$

NB: The amount of supervised laboratory hours stated for each course unit, which lasts for one semester, is for the formal laboratory class in which instructors are present to do demonstrations and to assist accounting students to do their laboratory exercises, assignments, or projects. 


\section{APPENDIX B}

\section{Course Descriptions of the Core Computer Courses}

\section{Computer programming}

(Lecture: 3 hours/week; Laboratory: 3 hours/week)

Topics: Elements of computer Systems; introduction to operating systems; text editors; algorithms; programming problem solving; programming methodologies: structured programming, top-down stepwise refinement, modular programming; syntax and features of COBOL; basic data and file structures; control structures; inputs and outputs; COBOL programming; program testing and debugging techniques; program documentation; overview of computer applications to business.

\section{End-User Computing}

(Lecture: 3 hours/week; Laboratory: 2 hours/week)

Topics: Word processing: functions of word processing, keyboard skills, use of text and graphics in documents, styles and presentations; Business graphics: histogram, bar chart, pie chart, etc; Desktop publishing; Spreadsheets: functions of spreadsheets, commands and conventions, macros, testing for errors; information center; management of end-user computing.

\section{Information Processing}

(Lecture: 3 hours/week; Laboratory: 3 hours/week)

Topics: Logical and physical file design; storage devices and their characteristics; sequential, indexed and direct organizations; file processing; data processing environments; systems analysis, design and implementation; systems life-cycle; systems development methodologies: data flow, entity-relationship, structured, prototyping, participative, phenomenological, evolutionary approaches; Jackson design methodology.

\section{Computer Systems and System Software}

(Lecture: 3 hours/week; Laboratory: 3 hours/week)

Topics: Computer architecture: functional components of computers, logic design, representations of numbers, arithmetic logic units, asynchronous and synchronous sequential circuit designs, bus systems, instruction sets, execution cycles, assembly language programming, associative, cache and virtual memories, memory addressing; Systems software: compilers and compiling techniques, linking loader, operating systems and resource management.

\section{Databases}

(Lecture: 3 hours/week; Laboratory: 3 hours/week)

Topics: Types of databases: hierarchical, network and relational data models; entity-relationship model; relational algebra and calculus; normalizations; data dictionary; data administration; database management systems; SQL; fourth generation languages and their use; query optimization; physical design databases; information resource management.

\section{Computer Networks}

(Lecture: 3 hours/week; Laboratory: 2 hours/week)

Topics: Local area and wide area networks; network; topology: bus, star, ring, tree; protocols: link layer protocols, medium access control protocols, IEEE 802 standards; high-speed local networks; circuit-switched local networks; open systems interconnection; data communications; internetworking principles and protocols; Ethernet, token ring, etc; gateways, bridges, filters, and repeaters; implementation considerations; reliability and security.

\section{Computer-Baud Accounting Information System}

(Lecture: 3 hours/week; Laboratory: 2 hours/week)

Topics: Business systems; information flow in business organization; information provision in functional areas; internal controls in accounting information systems; computerized ledgers and book-keeping; audittrail; utilization of accounting software packages; information management; office automation; security. 
Computer Auditing

(Lecture: 3 hours/week; Laboratory: 2 hours/week)

Topics: Objectives of auditing; auditor and society; technical, professional and legal frameworks; audit

procedures; Bayesian inference; audit of selected enterprises; investigation; approaches to computer auditing; controls in data processing environment; computer auditing tools and techniques: test data techniques, utility programs, code review, reverse engineering, compliance and substantive tests; concurrent auditing techniques; control and audit of microcomputer, minicomputer and mainframe computer systems; computer viruses; computer frauds; computer-related crimes; computer security.

\section{Expert Decision Support System}

(Lecture: 3 hours/week; Laboratory: 3 hours/week)

Topics: Expert systems: rule-based systems. forward and backward chainings, inference engines. knowledge representation; logical reasoning, fuzzy logic, probabilistic reasoning, knowledge acquisitions; Decision support systems (DSS): what is DSS, characteristics and components of DSS, types of problems, decision styles and personality. what-if analysis, four-stage process for developing DSS, predesign cycle, DSS applications, decision models, group DSS. anonymity and proximity factors; Expert decision support systems. 
إدخال الحاسب الآلي في مناهج المحاسبة

$$
\begin{aligned}
& \text { منق سي. إر } \\
& \text { جامعة الملك فهد للبزول والمعادن إد الميد } \\
& \text { الظهران - المملكة العربية السعودية }
\end{aligned}
$$

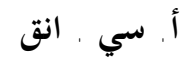

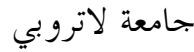

$$
\begin{aligned}
& \text { بندورا rم •r- أستر اليا }
\end{aligned}
$$

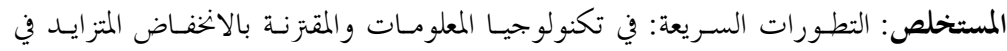

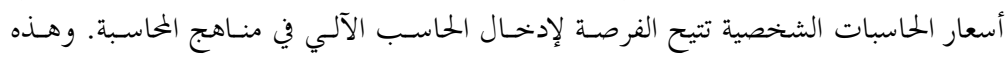

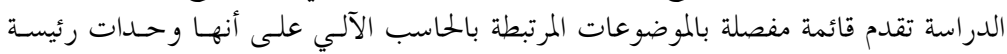

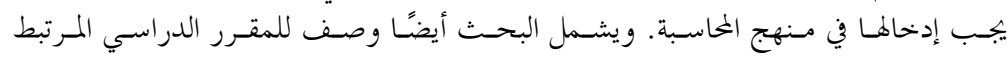

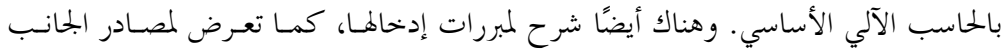

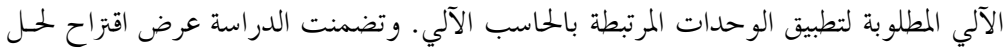

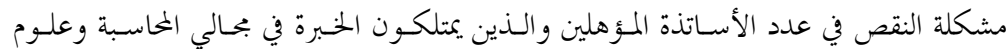

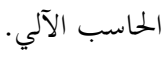

